
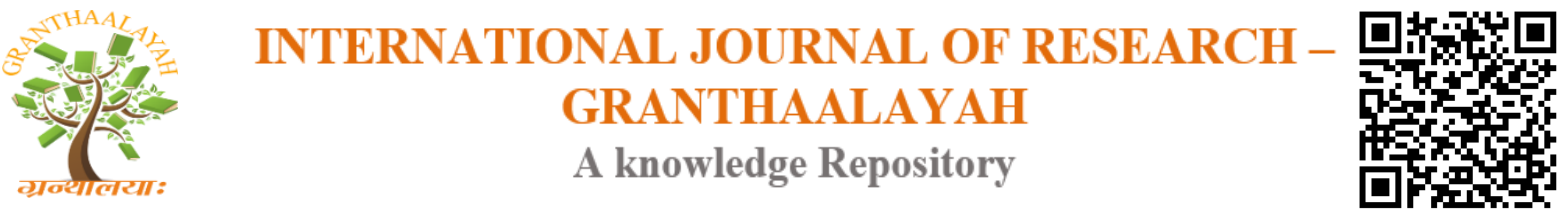

Science

\title{
CLONING AND EXPRESSION OF VACCINIA VIRUS PROTEIN (B18) IN HETEROLOGOUS HOST
}

\author{
Swaroop Sarkar ${ }^{1}$, V.V.S.Suryanarayana ${ }^{2}$ \\ ${ }^{1,2}$ Indian Veterinary Research Institute, Hebbal, Bangalore - 560024, India
}

\begin{abstract}
B18 is an immunoglobulin superfamily glycoprotein produced by vaccinia virus which resembles to interferon alpha receptors. It acts both in solution and also when associated with the cell surface. This B18 protein was expressed in heterologous host and purified based on affinity column chromatography. The purified B18 protein has been evaluated for biological activity in Pig Kidney- 15 cells (PK-15) which has been reported to have $\alpha$-interferon receptors and signaling mechanism. The CPE was more than $90 \%$ in the presence of protein and around $50 \%$ in the absence. B-18 can enhance the infectivity of FMDV to cells having $\alpha$-interferon receptors. This provides the basis for developing new strategies for improving attenuated vaccines and its capacity to act as an enhancer protein.
\end{abstract}

Keywords: Cloning; Expression; Vaccinia Virus B18; FMDV Virulence Enhancer.

Core Tip: Vaccinia viruses escape antiviral activity of host cell by producing an analogue which competes with the Type 2 interferon receptors on the cell surafce there by blocking the $\alpha$ interferon signalling mechnism. The analogous protein which is encoded by B-18 gene is a highly soluble glycoprotein with a structure similar to surface Igs. This protein can enhance the infectivity of FMDV to cells having $\alpha$-interferon receptors.

Cite This Article: Swaroop Sarkar, and V.V.S.Suryanarayana. (2017). "CLONING AND EXPRESSION OF VACCINIA VIRUS PROTEIN (B18) IN HETEROLOGOUS HOST." International Journal of Research - Granthaalayah, 5(8:SE), 57-71. https://doi.org/10.29121/granthaalayah.v5.i8(SE).2017.2249.

\section{Introduction}

Attenuated FMDV produced by deleting Lb-protease gene has shown to inhibit host translation mechanism at the fist instant by cleaving Initiation factor E (eIF-E) needed for cap dependent translation of the host and thereby allowing the expression of virus specific genes. However it may be necessary to substitute the lost biological activity of $\mathrm{L}$-protease in L-deleted virus for high titred attenuate virus production for using as vaccine. To achieve this we have identified vaccinia enhancer protein (B18) as the substitute for L protease effect. 
Vaccinia virus belongs to Orthopoxvirus genus of the Poxviridae family. It is a complex dsDNA viruses that replicates in the cytoplasm of the host cells and encodes proteins for DNA replication and gene expression (1,2). Viral infected cells modulates antiviral defence mechanism through intracellular immune modulators, apoptosis, the antiviral effects of IFNs, innate immune signalling and host gene transcription $(3,4,5)$. Interferons are made and released by cells infected with virus which causes nearby cells to elevate their anti-viral defence mechanism $(6,7,8)$. Conversely to evade the antiviral effects, VacV produces soluble interferon receptors and proteins that block the activities of interferon. These proteins are directed towards binding and disrupting the function of complement system, cytokines, chemokines and interferons $(9,10,11,12)$. Vaccinia expresses other proteins that are non-essential for viral replication but promotes virulence by inhibiting components of host immune response to infection, these five vaccinia virus Bcl-2 family proteins (N1, B14, A52, F1 and K7) inhibits the activation of interferon regulatory factor (IRF) $3(13,14)$. Two viral gene products B19 and B8 were shown to act as decoy receptors of type- 1 and type- 2 interferons, blocking the binding of interferons to its receptors (12). Highly attenuated modified vaccinia virus Ankara (MVA) showed that vaccinia virus mediated IFN inhibition is a multistep process involving several factors such as B18 and intracellular components that cooperate to efficiently shut off systemic IFN- $\alpha$ and IFN- $\beta$ responses $(15,16,17)$. B18 is an immunoglobulin superfamily glycoprotein which resembles to interferon alpha receptors. It act both in solution and also when associated with the cell surface (18). Therefore here we expressed B18 protein in heterologous host and the purified protein was used to enhance the infectivity of attenuated Foot-and-Mouth-Disease Virus.

\section{Materials and Methods}

\subsection{Amplification, cloning and expression of $B 18$ protein gene in E.coli}

Vaccinia virus expressing T7 polymerase was grown in BHK 21 cells as per standard protocol. The virus was partially purified by pelleting through $30 \%$ sucrose in TE in ultracentrif $\mu$ ge at 2,00,000 xg using Beckman Ti 50 rotor and the pellet was suspended in TE. The virus in the pellet was used for viral DNA extraction as per standard protocol. Briefly the virus pellet in 100ul suspension was subjected to Proteinase K treatment $(200 \mu \mathrm{g} / \mathrm{ml})$ in the presence of $0.5 \%$ SDS for $1 \mathrm{hr}$ at $37^{0} \mathrm{C}$. The viral DNA in the digest was extracted with phenol chloroform (1:1), dialysed against TE and used as a template for B18 amplification. The B18 gene was amplified with the primers, VacB18 (L) : 5' GCGCG GGT ACC CC ATG GCG ATG ACG ATG AAA ATG ATG GTA CAT A and VacB18(R) : 5' GG AAG CTT GGC GGC CGC CTC CAA TAC TAC TGT AGT TGT. An intense amplified DNA of $1.3 \mathrm{~Kb}$ could be seen in the gels which was purified, digested with Nco 1 and Hind 111 and ligated into Nco 1 and Hind 111 digested pET 28 A vector. The gene was sequenced and confirmed. Expression studies were conducted for B18 in E.coli. SDS PAGE analysis showed multiple bands corresponding to 40 to $120 \mathrm{kDa}$. Since the expression levels are poor and also being a glycoprotein it was felt necessary to express the protein in eukaryotic host. Therefore methanotrophic yeast, Pichia pastoris was selected as a heterologous host system due to its advantage of post translation modification such as proteolytic processing, folding, di-sulfide bond formation and glycosylation. 


\subsection{Cloning of Vaccinia enhancer protein gene (B18) in pPic9K transfer vector}

For cloning Vaccinia enhancer (B18) gene into P. pastoris, pPic 9K plasmid vector was used as transfer vector. The vector was digested with $\mathrm{SnaB} 1$ and Not1. The B18 gene of size $1.3 \mathrm{~Kb}$ which was cloned earlier in pcDNA was released from pc B18, and gel purified. The fragment was first digested with Kpn1 and a blunt end was created using T4 polymerase enzymes, the other end was digested with Not1 enzyme. This digested B18 was then ligated into pPic9k vector and transformed into TOP10 competent cells. The transformants were screened by colony lysis, colony PCR and restriction digestion methods. Finally the positive transformants were sequenced for positivity.

\subsection{Expression of B18 in Yeast Pichia pastoris GS115 cells}

Vaccinia enhancer gene in pPIC9k vector was first linearized with Sal1 and then transferred into Pichia GS115 competent cells by electroporation at field strength of $1.5 \mathrm{kV}$, and capacitance of $25 \mu \mathrm{f}$. The clones were screened by PCR. The positive clones were selected and protein expression by methanol induction. The expressed protein was confirmed by SDS page and one of the positive clones was grown in $100 \mathrm{ml}$ culture and expressed protein was purified by ammonium sulphate precipitation. The protein was characterized by SDS PAGE and biological assay by observing the effect on BHK 21 cells. Further high solubility nature of the protein was confirmed by the presence of the protein in the pellet even after extraction with Trizole reagent.

\section{Results}

\subsection{Amplification of vaccinia virus enhancer glyco protein gene $(\mathrm{B} 18)$ protein gene}

Vaccinia like other pox viruses escape antiviral activity of host cell by producing an analogue which competes with the Type 2 interferon receptors on the cell surafce there by blocking the $\alpha$-interferon signalling mechnism. The analogous protein which is encoded by B-18 gene is a highly soluble glycoprotein of around $40 \mathrm{kDa}$ with a structure similar to surface Igs . To produce attnuated FMDV we have deleted Lb protease gene of FMDV which has been shown to inhibit host translation mechanism at the fist instant by cleaving Initiation factor E (eIF-E) needed for cap dependent translation of the host and there by allowing the expression of virus specific genes,. However it may be necessary to substitute the lost biological activity of L-protease in L-deleted virus for high titred attenuate virus production for using as vaccine. To achieve this we have identified vaccinia enhancer protein as the substitute for L protease effect. The gene B18 of $1.3 \mathrm{~kb}$ was amplified from partially purified vaccinia virus available in FMD Research Lab (prviously called as Molecular Virology Lab), at Bangalore Campus of IVRI as described under Materials and methods. As seen in the Fig. 1, below an intense specific DNA band of size around $1.5 \mathrm{~kb}$ was seen in the gels. Single amplified band with no non specific amplified product shows that the primers are specific and the band may correspond to B18 gene of $1.3 \mathrm{~kb}$. 


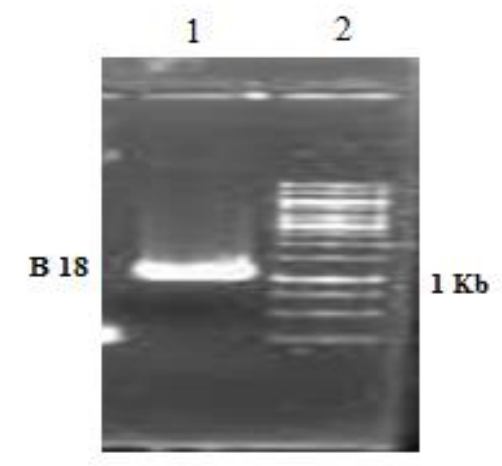

Fig: 1: PCR amplification of B-18 gene of vaccinia virus Lane 1: Amplified B 18 gene,

2: DNA molecular size markers (1 kb ladder)

The amplified DNA was purified from agarose gels and subjected for partial sequencing at Chromus Biotech sequencing facility, Bangalore, using forward primer. Asequnce of $790 \mathrm{nts}$ were read from the ladder sequence (Fig. 2).

AAGGAGATATACCATGGCGATGACGATGAAAATGATGGTACATATATATTTCGTA TCATT ATTGTTATTGCTATTCCACAGTTACGCCATAGACATCGAAAATGAAATCACAGAA TTCTT

CAATAАAАTGAGAGATACTCTACCAGCTAAAGACTTTAAATGGTTGAATCCAGC ATGTAT

GTTCGGAGGCACAATGAATGATATAGCCGCTCTAGGAGAGCCATTCAGCGCAA AGTGTCC

TCСTATTGAAGACAGTCTTTTATCGCACAgATATAAAGACTATGTGGTTAAATG GGAAAG

GCTAGAAAAAAATAGACGGCGACAGGTTTCTAATAAACGTGTTAAACATGGTG ATTTATG

GATAGCCAАCTATACATCTAАATTCAGTAACCGTAGGTATTTGTGCACCGTAAC TACAAA

GAATGGTGACTGTGTTCAGGGTATAGTTAGATCTCATATTAGAAAACCTCCTTC ATGCAT TCCAАAАACATATGAACTAGGTACTCATGATAAGTATGGCATAGACTTATACTG TGGAAT TCTTTACGCAАAАCATTATAАTАATATAACTTGGTATAAAGATAATAAGGAAAT TAATAT CGACGACATTAAGTATTCACAAACGGGAAAGGAATTAATTATTCATAATCCAGA GTTAGA

AGATAGCGgAAGATACGACTGTTACGTTCATTACGACGACGTTAGAATCAAGA ATGATAT

CGTAGTATCAAGATGTAAAATACTTACGGTTATACCGTCACAAGACCACAGGTT TAAACT

AATACTAGATCCAAAAATCAA ----

Fig. 2: Partial nucleotide sequence of $B-18$ protein gene of vaccinia. 
The initiation codon has been underlined. Four methionine residues which are in frame have been underlined. Six Leu residues are shown in italics and underlined.

The sequence was aligned with the published B18 R sequence of vaccinia virus which showed 99\% homology (Fig.3). As seen in the alignment the sequence aligned with the $19^{\text {th }}$ nucleotide indicating the amplified product has $\mathrm{N}$-terminal amino acid sequence. The total size of the gene as per the literature is $1293 \mathrm{nts}$ and the amplified product size was found to be around 1300 which indicates tha full length gene has been amplified. The aligment which starts at $19^{\text {th }}$ nucleotide follows an ATG codon

Alignment statistics for match \#1

$\begin{array}{lllll}\text { Score } & \text { Expect } & \text { Identities } & \text { Gaps } & \text { Strand } \\ 1441 \operatorname{bits}(780) & 0.0 & 782 / 783(99 \%) & 0 / 783(0 \%) & \text { Plus/Plus }\end{array}$

Query 19

GATGACGATGAAAATGATGGTACATATATATTTCGTATCATTATTGTTATTGCTATTC CA

Sbjc

GATGACGATGAAAATGATGGTACATATATATTTCGTATCATTATTGTTATTGCTATTC CA

Query

CAGTTACGCCATAGACATCGAAAATGAAATCACAGAATTCTTCAATAAAATGAGAG ATAC

Sbjct

CAGTTACGCCATAGACATCGAAAATGAAATCACAGAATTCTTCAATAAAATGAGAG ATAC

Query

TCTACCAGCTAAAGACTTTAAATGGTTGAATCCAGCATGTATGTTCGGAGGCACAAT GAA

Sbjct

TCTACCAGCTAAAGACTCTAAATGGTTGAATCCAGCATGTATGTTCGGAGGCACAAT GAA

Query

TGATATAGCCGCTCTAGGAGAGCCATTCAGCGCAAAGTGTCCTCCTATTGAAGACAG TCT

Sbjct

TGATATAGCCGCTCTAGGAGAGCCATTCAGCGCAAAGTGTCCTCCTATTGAAGACAG TCT

Query

TTTATCGCACAGATATAAAGACTATGTGGTTAAATGGGAAAGGCTAGaaaaaaaTAGAC G

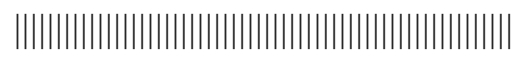


Sbjct 360

TTTATCGCACAGATATAAAGACTATGTGGTTAAATGGGAAAGGCTAGAAAAAAATA GACG

Query

GCGACAGGTTTCTAATAAACGTGTTAAACATGGTGATTTATGGATAGCCAACTATAC ATC

Sbjct 420 GCGACAGGTTTCTAATAAACGTGTTAAACATGGTGATTTATGGATAGCCAACTATAC ATC

Query

TAAATTCAGTAACCGTAGGTATTTGTGCACCGTAACTACAAAGAATGGTGACTGTGT TCA

Sbjct

TAAATTCAGTAACCGTAGGTATTTGTGCACCGTAACTACAAAGAATGGTGACTGTGT TCA

Query

GGGTATAGTTAGATCTCATATTAGAAAACCTCCTTCATGCATTCCAAAAACATATGA ACT

Sbjct

GGGTATAGTTAGATCTCATATTAGAAAACCTCCTTCATGCATTCCAAAAACATATGA ACT

Query

AGGTACTCATGATAAGTATGGCATAGACTTATACTGTGGAATTCTTTACGCAAAACA TTA

Sbjct

AGGTACTCATGATAAGTATGGCATAGACTTATACTGTGGAATTCTTTACGCAAAACA TTA

Query

TAATAATATAACTTGGTATAAAGATAATAAGGAAATTAATATCGACGACATTAAGT ATTC

Sbjct |||||||||||||||||||||||||||||||||||||||||||||||||||||||||||

TAATAATATAACTTGGTATAAAGATAATAAGGAAATTAATATCGACGACATTAAGT ATTC

Query

ACAAACGGGAAAGGAATTAATTATTCATAATCCAGAGTTAGAAGATAGCGGAAGAT ACGA

Sbjct

ACAAACGGGAAAGGAATTAATTATTCATAATCCAGAGTTAGAAGATAGCGGAAGAT ACGA 
CTGTTACGTTCATTACGACGACGTTAGAATCAAGAATGATATCGTAGTATCAAGATG TAA

Sbjct

CTGTTACGTTCATTACGACGACGTTAGAATCAAGAATGATATCGTAGTATCAAGATG TAA

AATACTTACGGTTATACCGTCACAAGACCACAGGTTTAAACTAATACTAGATCCAAA AAT

Sbjct |||||||||||||||||||||||||||||||||||||||||||||||||||||||||||

AATACTTACGGTTATACCGTCACAAGACCACAGGTTTAAACTAATACTAGATCCAAA AAT

Query 799 CAA 801<smiles>[C]#C</smiles>

Sbjct 900 CAA 902

Fig. 3: Nucleotide sequence alignment of the partial sequence of the amplified B-18 gene

The whole B-18 sequence was translated using NCBI programme and a protein sequence of $351 \mathrm{nts}$ were obtained which corresponds to $1053 \mathrm{nts}$ length with an approximate molecular weight of around $40 \mathrm{kd}$. The derived aa sequence as shown below (Fig. 4) has 6 methionin residues and several leucin residues. The protein as per the sequence has a number of basic aa. The protein has 9 cystein residues indicating the possibility of $\mathrm{S}-\mathrm{S}$ bond formation and multimerization. There are $5 \mathrm{~N}$-glycosylation sites, the protein has immunoglobulin like motifs and secretary signals (Fig not shown) as per literature it is analogous to alpha interferon receptors. Therefore as envisaged the protein may be useful to inhibit antiviral effect of the cells by competing with alpha interferon receptors on the cell surface.

MTMKMMVHIYFVSLLLLLFHSYAIDIENEITEFFNKMRDTLPAKDSKWLNPACMFGGT MNDIAALGEPFSAKCPPIEDSLLSHRYKDYVVKWERLEKNRRRQVSNKRVKHGDLWIA NYTSKFSNRRYLCTVTTKNGDCVQGIVRSHIRKPPSCIPKTYELGTHDKYGIDLYCGILY AKHYNNITWYKDNKEINIDDIKYSQTGKELIIHNPELEDSGRYDCYVHYDDVRIKNDIVV SRCKILTVIPSQDHRFKLILDPKINVTIGEPANITCTAVSTSLLIDDVLIEWENPSGWLIGFD FDVYSVLTSRGGITEATLYFENVTEEYIGNTYKCRGHNYYFEKTLTTTVVLE

MTMKMMVHIYFVSLLLLLFHSYAIDIENEITEFFNKMRDTLPAKDSKWLNPACMF GGTMNDIAALGEPFSAKCPPIEDSL 80 LSHRYKDYVVKWERLEKNRRRQVSNKRVKHGDLWIANYTSKFSNRRYLCTVTTK NGDCVQGIVRSHIRKPPSCIPKTYEL 160 GTHDKYGIDLYCGILYAKHYNNITWYKDNKEINIDDIKYSQTGKELIIHNPELEDSG RYDCYVHYDDVRIKNDIVVSRCK 240 ILTVIPSQDHRFKLILDPKINVTIGEPANITCTAVSTSLLIDDVLIEWENPSGWLIGFD FDVYSVLTSRGGITEATLYFE 320 
NVTEEYIGNTYKCRGHNYYFEKTLTTTVVLE

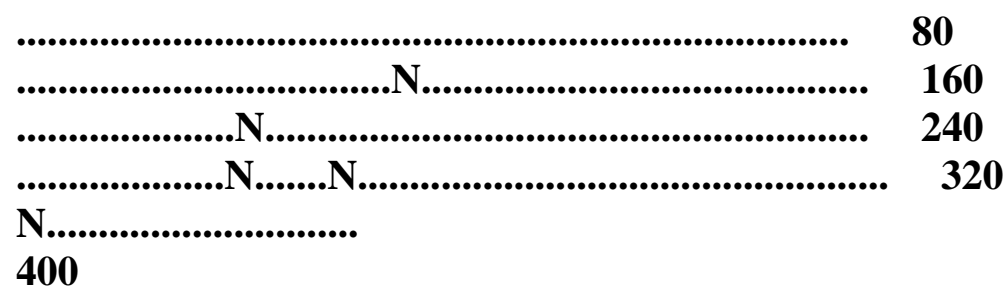

Fig. 4: The derived aa sequence and the predicted N-glycosylation sites of vaccinia B-18 protein.

\subsection{Cloning and Expression of B-18 protein in heterologous host system In E.coli}

The amplified DNA of $1.3 \mathrm{~Kb}$ was purified, digested with Nco 1 and Hind III and ligated into Nco 1 and Hind III digested pET 28 A vector and transferred into E.coli DH5 alpha. The transformants were screened by PCR and the positive clones were selected, recombinant plasmid purified sequenced and confirmed by sequence analysis. The recombinant plasmid was transferred into E.coli BL21DE3 pLys cells for protein expression. Four positive clones were grown in LB broth and induced with IPTG $(0.2 \mathrm{mM})$. Up on SDS PAGE analysis a faint band of size of around $40 \mathrm{kDa}$ was seen in the gel indicating the expression of B-18 in the clone. Though there was an additional protein bands that could be seen in the gels, the intensity was very less indicating that expression levels were very low (Fig not shown). This may be due to the high basic nature. Hence it has been proposed to express the protein with a 5 ' fusion tag in pET32 vector. The gene was cloned in pET 32 vector, the recombinants were screened initially by colony PCR and colony lysis. Plasmid from one of the colonies was prepared, digested with Nco 1 and Xho 1 and digest was anlysed by $1 \%$ agarose gel electrophoresis using DNA molecular size markers. As seen in the Fig.5, below, an insert of $1.3 \mathrm{~kb}$ was released from the pET B18. The plasmid was used for protein expression after transferring into E.coli BL21DE3 pLys cells.

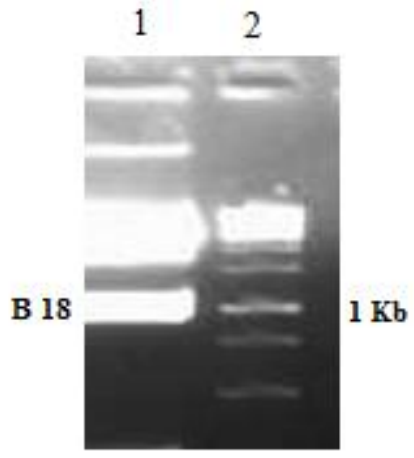

Fig. 5: Agarose gel electrophoresis of Nco 1 , Xho 1 digested pET 32 A with B-18 insert

The expressed protein was affinity purified thro $\mu$ gh Nickel NTi agarose column. Protein of size $62 \mathrm{kDa}$ could be seen in the gels (Fig not shown) which corresponds to the size of Vac B-18protein of $47 \mathrm{kDa}$ plus fusion Tags of size $15 \mathrm{Kda}$. Quantity of protein produced from the clone 
was estimated to be of $1.0 \mathrm{mg}$ from $20 \mathrm{ml}$ culture. Low levels of expression may be due to the nature of the protein. The protein was used for raising antiserum in rabbits.

\section{In Pichia pastoris}

The Vaccinia enhancer protein, B18 has been reported to be a soluble secretary glycoprotein which is analogous to alpha interferon receptor. The three dimensional structure as per published report is like cell surface Ig receptor. Previously expressed using Pet 32 vector in E.coli BL21DE3 pLys but the protein expressed was not sufficient to raise anti-serum in rabbit hence eukaryotic expression system Pichia Pastoris was selected due to their advantage of post translation modification such as proteolytic processing, folding, di-sulfide bond formation and glycosylation.

\section{Cloningof B-18 gene in PPic9K transfer vector:}

The B18 gene of size $1.3 \mathrm{~Kb}$ previously cloned in pCDNA carring was first digested with Kpn1 and blunt ended using T4 polymerase, later the gene was released with Not1 enzyme. The insert was purified from gel and then ligated into pPic9k vector previously digested with Sna B 1 and Not 1, transferred into TOP10 competent cells and plated on Amp LB agar plate. Several transformants were obtained which may carry plasmid with or without $1.3 \mathrm{~kb}$ insert. Initially the transformants were screened by colony lysis, (Fig.6)

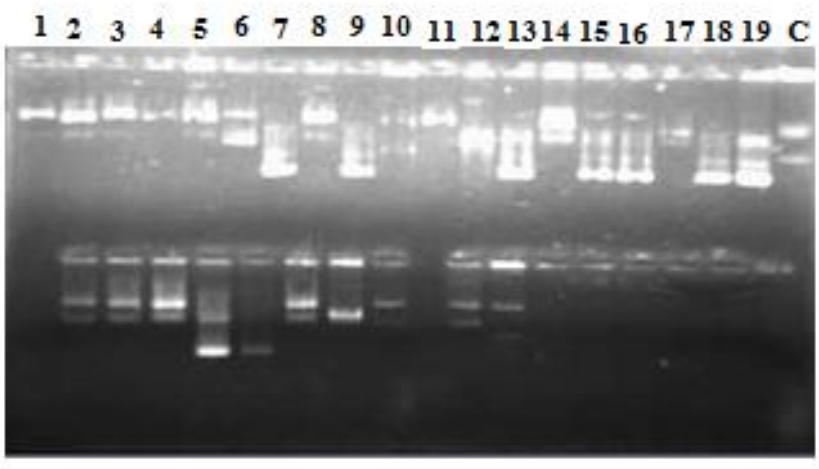

Fig. 6: Colony lysis of TOP 10 transformants carrying $\mathrm{pPic} 9 \mathrm{~K}$ vector with or without

\section{B-18 gene}

As seen in the Fig above of the 30 colonies screened about 20 colonies showed the presence of the plasmid which moved slower than the vector control (last colony on the top row). However there are colonies which carry plasmid whose mobility is faster than the vector control. These plasmids may correspond to the contaminant pCDNA with $1.3 \mathrm{~kb}$ insert as the insert was purified from the recombinant pCDNA. Hence the colonies which showed the presence of plasmid with slowest mobility were selected for further screening by colony PCR (Fig. 7) 


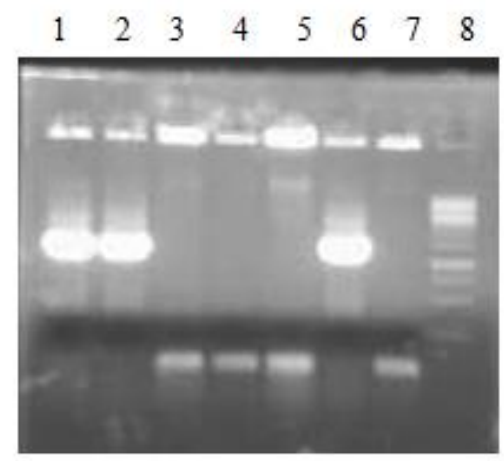

Fig. 7: Colony PCR of the $\mathrm{pPic} 9 \mathrm{~K}$ recombinants with or without $1.3 \mathrm{~kb}$ insert. Lane 1-7 positive colonies by colony lysis, Lane: 8 , lKb DNA size marker.

As seen in the Fig. 63 above of the 7 positive colonies by colony lysis 3 showed the intense amplification of above $1.0 \mathrm{~kb}$ fragment by colony PCR using insert specific primers indicating these colonies carry B-18 insert. The negative colonies may carry only vector. Plasmid from the positive colonies prepared and further screened by restriction digestion with No1 and Bam H1 for the release of $1.3 \mathrm{~kb}$ insert. (Fig. 8)

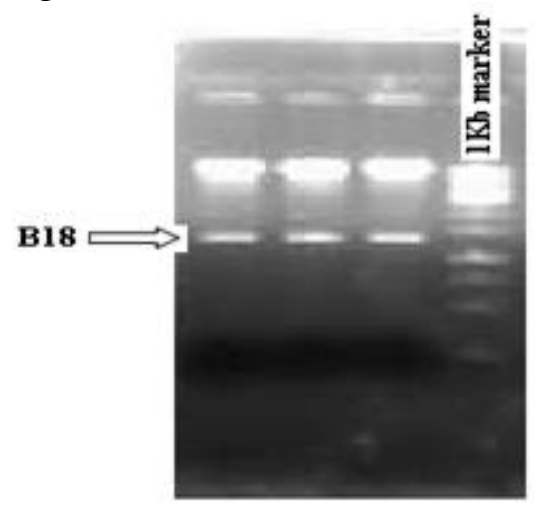

\section{Fig. 8: Not 1 and $\mathrm{Bam} \mathrm{Hl}$ digested $\mathrm{pPic} 9 \mathrm{~K}$ with $\mathrm{B}-18$ insert}

As seen in the Fig. 8 all the 3 positive colonies showed the release of the insert of $1.3 \mathrm{~kb}$ along with the vector size of above $9 \mathrm{~kb}$ corresponding to $\mathrm{pPic} 9 \mathrm{~K}$, when digested the purified plasmids with Not 1 and Bam h1. Finally the positive transformants were sequenced and confirmed. The plasmid was designated as pPic 9B18

\section{Protein expression in Pichia pastoris GS115 cells}

The pPic9 B18 plasmid was first linearized with Sal1 and then transferred into yeast, GS115 competent cells by electroporation. The transformants were selected on Histidine minus minimal medium agar plates and the clones were screened for the presence of insert by PCR using genomic DNA isolated from individual colonies. The three positive clones were grown in YPD and induced for protein expression with methanol. Time course studies were conducted for optimum expression adding methanol at every $24 \mathrm{hr}$. Ammonium sulphate precipitated proteins 
in the supernatants were subjected for SDS PAGE anlysis (Fig. 9) using standard protein molecular weight markers. As seen in the Fig. 9 no secretary proteins were observed in the culture medium $24 \mathrm{hr}$ post induction. This may be due to the low concentration of the protein accumulated at $24 \mathrm{hr}$ post induction. (A, lane 1, 2, 3). However after $48 \mathrm{hr}$ of induction Clone 1, 3 showed better expression than Clone 2. After $48 \mathrm{hr}$ post induction several protein bands have been observed in the CBB stained gels, however more intense band was observed at around 50 $\mathrm{kDa}$ which may correspond to the expressed B-18. Other smaller sized proteins may be of vector or host origin. At $72 \mathrm{hr}$ post induction Clone 2 and 3 showed intense protein bands and Clone 1 showed less intense bands. This anomaly may be due to inconsistency in the protein precipitation or collection of the precipitate by centrifugation or both. After 96 and $120 \mathrm{hr}$ post induction the observed concentration of the $50 \mathrm{kDa}$ protein is almost similar in the case clone 1 and 2 . Hence clone 1 and 2 were selected for subsequent studies. The optimum time at which the highest protein expression was observed is $96 \mathrm{hr}$ post induction. Hence Clone 1 and 2 were selected for protein production and purification of expressed protein for subsequent use. The additional protein bands may also due to premature termination or initiation of protein expression or due to the presence of secretary signals in the protein resulting in the cleavage of the signal peptides.

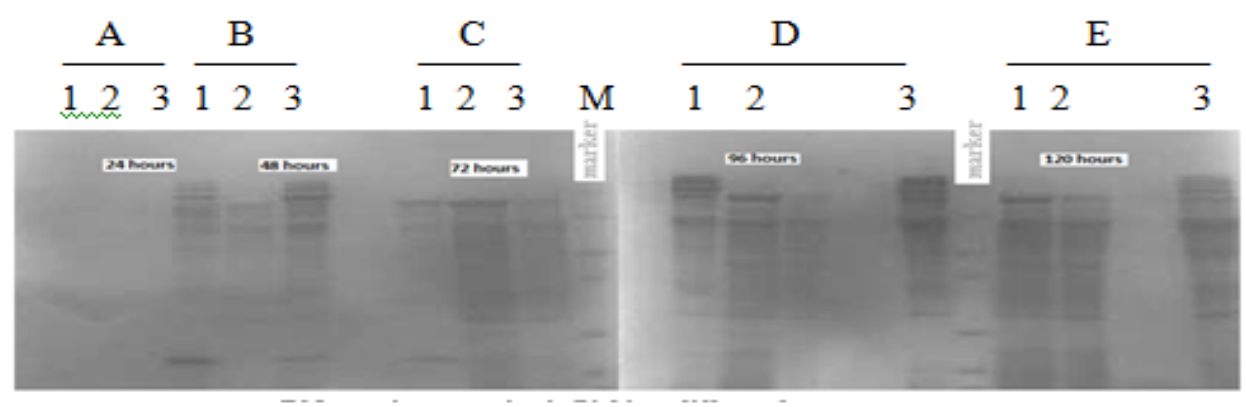

Fig. 9: Time course studies on B-18 expression in Pichia pastoris after induction with Methnol

Lane 1,2,3 represents Clone 1,2 and 3 respectively . A,B,C,D,E corresponds to protein expression after 24, 48,72, 96 and $120 \mathrm{hr}$ after the addition of methnol respectively from clone $1,2,3$

The clones 2 (sample 1) and 1 were grown in 100ml cultures, induced for expression for $96 \mathrm{hr}$ and the expressed proteins were purified by ammonium sulphate precipitation. As seen in the Fig. 10 below, a protein band of around $50 \mathrm{kDa}$ was precipitated as a major band along with other minor bands. As observed in the time course studies (Fig. 9) the $50 \mathrm{kDa}$ may correspond to the B-18. While minor bands may correspond to the translated products from the same gene but with different ATG codons which are in frame. The high molecular protein bands may correspond to the multimerized B-18 as the protein has has several cystein residues. The observed size of major band is around $50 \mathrm{kDa}$ and the molecular weight as per the amino acid sequence is around $40 \mathrm{kDa}$. The difference of $10 \mathrm{kDa}$ may be due to the glycosylation of the protein in Pichia pastoris. The protein as per aa sequence has 5 potent $\mathrm{N}$-glycosylation sites. To confirm the high solubility nature of the protein, the ammonium sulphate precipitated and dialyzed protein was extracted with Trizole reagent, the aqueous phase was collected, mixed with $2.5 \mathrm{vol}$ of isopropanol, the precipitate was collected by centrifugation and analyzed by SDSPage. Clear protein band of $50 \mathrm{kDa}$ was observed in the CBB stained gel (Fig not shown) confirming the high solubility of the B-18. 


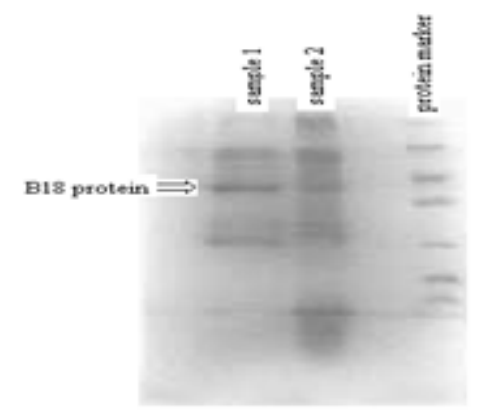

Fig. 10: Ammonium sulphate precipitated Pichia expressed B-18 protein

Lane 1,2. Ammonium sulphate precipitated precipitated proteins from clone 1 and 2 respectively. Lane 3. Protein molecular weight markers.

Biological function of the protein, as observed by its role in interfereing $\alpha$-interferon signalling mechnism by way of enhancing infectivity was checked in BHK cells as preliminary studies. The protein when added to the medium at a concentration $>1 \mu \mathrm{g} / \mathrm{ml}$ the cells showed toxic effect. Hence the concentation at which the protein shows minimum lethal toxic effect to BHK cells was evaluated in which was found to be $<0.5 \mu \mathrm{g} / \mathrm{ml}$. Subsequently the effect of the protein on virus infection was tested by incubating the BHK cells with <1 pfu FMDV BioAsia along with $0.33 \mu \mathrm{g} / \mathrm{ml}$ protein. After $48 \mathrm{hr}$ pi the cells were observed under inverted microscope at 100x magnification (Fig . 11). As seen in the Fig.67 the virus infected cells monolayers showed rounding and bulging (Palte A and B) which is not seen in the case of mock infected cells (Plate C). However the number of cells that became rounded due to the virus infection (cpe ) was higher in the presence of the protein ( Plate A) as compared to in absence (plate B). However, as expected, the diffetrence is not significant, due to the inherant deficiency of $\alpha$-interferon signalling mechnism in BHK cells because of the presnce of a few $\alpha$-interferon receptors. The mock infected cells did not show any change in cell morphology indicating there is no cpe. The protein may be evaluated in other cell systems and viruses for its use in vaccine production. The protein may also be evaluated in Lb deleted Chimeric ' $\mathrm{O}$ ' for its use in developing attenuated (Lb deleted) FMDV

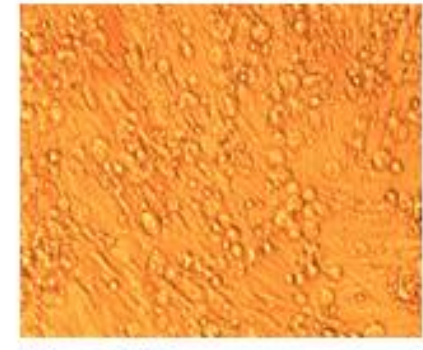

A) + B-18

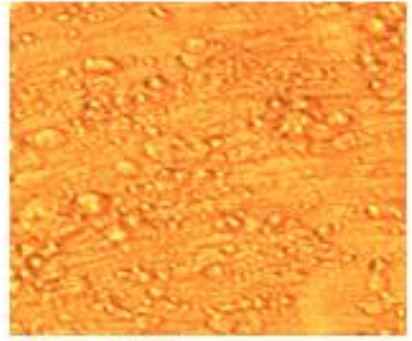

B) $-\mathrm{B} 18$

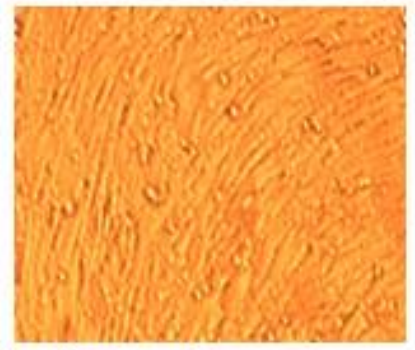

C) cell control

Fig.11: Infectivity of FMDV Bio-Asia in presence and in absence of B-18 protein to BHK cells

Plate A, BHK cells infected with Bio-Asia in presence of B-18 protein, ; B, infected with Bio-Asia in absence of B-18 protein; C. Mock infected BHK cells. 
The protein has been evaluated for biological activity in Pig Kidney- 15 cells (PK-15) which has been reported to have $\alpha$-interferon receptors and signalling mechnism. As seen in the Fig. 12 $\mathrm{A}$, the cpe is more than $90 \%$ in the presence of protein and around $50 \%$ in the absence. As expected B-18 can enhance the infectivity of FMDV to cells having $\alpha$-interferon receptors. The virus titration need to be to done to know the extent of enhancement in the titre.

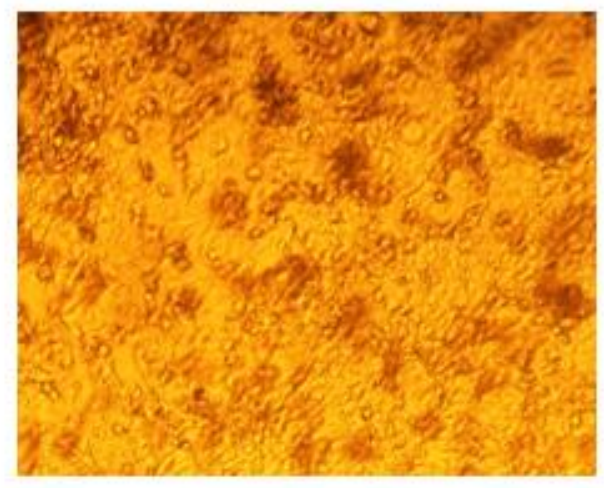

A) + B-18

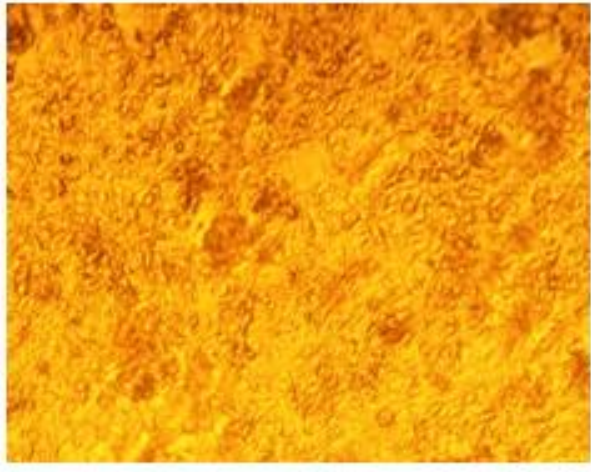

B) $-\mathbf{B}-18$

Fig. 12: Infectivity of FMDV Bio-Asia in presence and inabsence of B-18 protein to PK cells

\begin{abstract}
Plate A, PK-15 cells infected with Bio-Asia in presence of B-18 protein,; B, infected with Bio-Asia in absence of B-18 protein.
\end{abstract}

\title{
4. Discussion
}

To augment the low replication efficiency of the virus produced through L-deleted genome we propose to add externally the analogous protein which can mimic alpha interferon receptos present on the cell surface. Based on the available literature we have identified vaccinia enhancer protein encoded by B-18 gene. The B-18 protein gene was amplified from the purified vaccinia virus and the amplified gene was confirmed by sequence analysis. Since it is a soluble glycoprotein, we expressed the protein in eukaryotic host, Pichia pastoris to achieve glycosylation.. Several proteins requiring post transltional modification were expressed in this system. Since the protein has secretary signals and Ig like structure with several methionin residues the level of expression is low. Expression of vaccinia B-18 in insect cell system using Baculovirus expression system was carried out by other scientific group and the functionality of the protein in enhancement of virulence was confirmed using the deletion mutant. Up on in silico analysis of the motifs in the derived amino acid sequence of the protein it was observed that the protein has Ig like surface receptor structure that can bind to cytokines like alpha interferon, IL2 etc indicating that the enhancer protein competes with the surface receptor for interferon binding thereby inhibiting the antiviral response of the host cell. We conducted infectivity studies in BHK cells using FMDV Bio-Asia 1 virus (Fig 11). Though the protein showed the enhancement in infectivity of the virus the level of enhancement was not significant. This is because of the lack or presence of poor $\alpha$-interferon signaling mechanism in BHK cells. We therefore extended the studies using PK-15 cells which have confirmed $\alpha$-interferon signalling mechnism. As expected the cpe was almost $90 \%$ in the presence of the protein and is only $50 \%$ in absence of 
the protein. However it is necessary to study the effect of the protein on infectivity of L-deleted Chimeric virus. The protein may also be used in the development of other viral vaccines which employ cell lines other than BHK for virus production.

\section{Conclusion}

To augment efficiency for high titred virus production we have made an approach of interfering $\alpha$-interferon signaling mechanism by external supply of the enhancer protein, B-18 which is expressed by Vaccinia virus. This soluble glycoprotein gene was amplified from vaccinia, cloned in Pichia pastoris, expressed and studied. Though the protein has a little effect on BHK cells which is deficient in $\alpha$-interferon signaling mechanism, this may be useful in other cell systems used for vaccine production.

\section{Acknowledgement}

The financial assistance from the department of Indian Council of Agricultural Research, Pusa, New Delhi, is gratefully acknowledged. We thank the Director, Indian Veterinary Research (IVRI), Izatnagar, Bareilly and the Joint Director, IVRI, Bangalore Campus, India, for providing the facility to carry out this work.

\section{Authors Contribution}

V.V.S.Suryanarayana designed the report and planned the work; Swaroop Sarkar performed the bench work; V.V.S.Suryanarayana analysed the data; Swaroop sarkar and V.V.S.Suryanarayana wrote the paper.

\section{Supported by}

Indian Council of Agricultural Research (ICAR), New Delhi, Director, Indian Veterinary Research (IVRI), Izatnagar, Bareilly and Joint Director, IVRI, Bangalore Campus, India

\section{Institutional Review Board Statement}

The study was reviewed by ICAR and Staff Research Council (SRC) of IVRI, Bangalore.

\section{Conflict-of-Interest Statement}

V.V.S.Suryanarayana has received research funding for this project under Emeritus Scientist Scheme from ICAR, New Delhi. Swaroop Sarkar was a Senior Research Fellow worked under the project at Indian Veterinary Research Institute, Hebbal, Bangalore.

\section{References}

[1] Condit R.C., Moussatche N., Traktman P. In a nutshell: structure and assembly of the vaccinia virion. Adv. Virus Res. 2006;66:31-124. [PubMed: 16877059]

[2] Moss B. Poxviridae: the viruses and their replication. In: Knipe D.M., editor. Fields Virology. Lippincott Williams \& Wilkins; Philadelphia: 2007. pp. 2905-2946. 
[3] Haga, I.R., and A.G. Bowie, 2005. Evasion of innate immunity by vaccinia virus. Parasitology 130 Suppl. S11-25.

[4] Seet B.T., Johnston J.B., Brunetti C.R., Barrett J.W., Everett H. Poxviruses and immune evasion. Annu. Rev. Immunol. 2003;21:377-423. [PubMed: 12543935]

[5] Taylor J.M., Barry M. Near death experiences: poxvirus regulation of apoptotic death. Virology. 2006;344:139-150. [PubMed: 16364745]

[6] Deonarain R, et al. 2000. Impaired antiviral response and alpha/beta interferon induction in mice lacking beta interferon. J. Virol. 74:3404-3409.

[7] MullerU,etal. 1994. Functional role of type I and type II interferons in antiviraldefense.Science264:1918-1921.

[8] Rodriguez JR, Rodriguez D, Esteban M. 1991. Interferon treatment inhibits early events in vaccinia virus gene expression in infected mice. Virology 185:929-933.

[9] Alcami A. Viral mimicry of cytokines, chemokines and their receptors. Nat. Rev. Immunol. 2003;3:36-50. [PubMed: 12511874]

[10] Alcami A., Koszinowski U.H. Viral mechanisms of immune evasion. Immunol. Today. 2000;21:447-455. [PubMed: 10953097]

[11] McFadden G., Murphy P.M. Host-related immune modulators encoded by poxviruses and herpesviruses. Curr. Opin. Microbiol. 2000;3:371-378. [PubMed: 10972497]

[12] Perdiguero B., Esteban M. The interferon system and vaccinia virus evasion mechanisms. J. Interferon Cytokine Res. 2009;29:581-598. [PubMed: 19708815]

[13] BJ Ferguson, CTO Benfield, H Ren, VH Lee, GL Frazer, P Strnadova, RP Sumner, GL Smith Journal of General Virology, 94 (9), 2070-2081

[14] Ron A.-J. Chen, Nathalie Jacobs and Geoffrey L. Smith. Vaccinia virus strain Western Reserve protein B14 is an intracellular virulence factor, (2006), 87, 1451-1458

[15] Zoe Waibler, Martina Anzaghe, Theresa Frenz, Astrid Schwantes, Christopher Po"hlmann, Holger Ludwig, Marcos Palomo-Otero, Antonio A. Vaccinia Virus-Mediated Inhibition of Type I Interferon Responses Is a Multifactorial Process Involving the Soluble Type I Interferon Receptor B18 and Intracellular Components $\square$. JOURNAL OF VIROLOGY, Feb. 2009, p. 1563-1571

[16] Colamonici, O. R., P. Domanski, S. M. Sweitzer, A. Larner, and R. M.Buller. 1995. Vaccinia virus B18R gene encodes a type I interferon-binding protein that blocks interferon alpha transmembrane signalling .J.Biol.Chem. 270:15974-15978.

[17] Symons, J. A., A. Alcamí, and G. L. Smith. 1995. Vaccinia virus encodes a soluble type I interferon receptor of novel structure and broad species specificity. Cell 81:551-560.

[18] Alcamí, A., J. A. Symons, and G. L. Smith. 2000. The vaccinia virus soluble alpha/beta interferon (IFN) receptor binds to the cell surface and protects cells from the antiviral effects of IFN. J. Virol. 74:11230-11239. 